\title{
Compact Modified Ground Plane (MGP) Microstrip Antenna with Narrowband and Wideband Resonance Characteristics
}

\author{
Sudipta Das ${ }^{1 *}$, Partha Pratim Sarkar ${ }^{2}$ and Santosh Kumar Chowdhury ${ }^{3}$ \\ $I^{*}$ Department of ECE, IMPS CET, Malda, W.B, INDIA \\ ${ }^{2}$ Department of Engineering and Technological Studies, University of Kalyani, \\ Nadia, W.B, INDIA \\ ${ }^{3}$ Ex-Professor, Department of Electronics and Tele-Communication Engineering, \\ Jadavpur University, Kolkata, W.B, INDIA \\ 1*Sudipta.das1985@gmail.com, ${ }^{2}$ parthabe91@yahoo.com, ${ }^{3}$ santoshkumarchowdhur \\ $y @$ gmail.com
}

\begin{abstract}
A single layer, coaxial probe feed slotted microstrip patch antenna with modified ground plane has been designed and analyzed. The ground plane of the antenna is modified by incorporating an open-ended asymmetric T-shaped slot. The proposed antenna depicts narrowband and wideband resonance characteristics due to the modified structure. The miniaturized antenna dimension is only about $30\left(0.645 \lambda_{r}\right) \times 20\left(0.430 \lambda_{r}\right)$ $\mathrm{mm}^{2}$, where $\lambda_{r}$ is the wavelength of the resonant frequency of the conventional antenna (i.e., 6.45GHz). The measured result shows that the proposed antenna exhibits $-10-d B$ wide impedance bandwidth of $62.3 \%$ from 2.53 to $4.82 \mathrm{GHz}$ and two distinct narrow resonant frequencies at 6.165 and $8.18 \mathrm{GHz}$ due to modifications in the ground plane. The size of the proposed antenna has been reduced by $70 \%$ in comparison to the conventional rectangular microstrip antenna with same patch area. An extensive analysis of the antenna parameters (reflection coefficient, VSWR, radiation pattern, gain, directivity, radiation efficiency etc.) including surface current distribution is presented in this paper. The proposed antenna could be promising for a number of modern wireless communication applications due to its small size, low cost and wide operating bandwidth.
\end{abstract}

Keywords: Compact, modified ground plane, narrowband, wideband, wireless communication

\section{Introduction}

Microstrip patch antennas (MPAs) are popular for wireless communication applications due to their well-known attractive features, such as low profile, light weight, conformable to planar and non-planar surfaces, simple and inexpensive to manufacture using modern printed-circuit technology, mechanically robust when mounted on rigid surfaces and compatible with MMIC designs. Apart from its various attractive features, microstrip patch antenna suffers from an inherent limitation of narrow impedance bandwidth typically of about $2-4 \%$. However, in some applications, such as in astronomy, cognitive radio and government security systems, narrow bandwidths are desirable. Several narrowband microstrip antennas are reported by researchers [1-4]. But the increasing demands for wireless connectivity in modern wireless communication systems necessitate a single antenna to cover several allocated wireless frequency bands. The usage of many antennas is usually limited by the volume and cost constraints of the applications. Researchers have offered numerous techniques for bandwidth enhancement of microstrip patch antennas to support multiple wireless communication systems using single antenna. These techniques include use of shorting pin [5], aperture coupling [6], 
stacked patch [7], staggering effect [8], modified feed [9], thick foam substrate [10], fractal slots [11], PBG structure [12], and slots on the radiating patch [13] to enhance the bandwidth of microstrip antennas. The combinations of radiating patch and the ground plane slots [14] were also analyzed to achieve compact broadband operation. W. Cao et.al [5] proposed a broadband microstrip antenna loaded with shorting pin but only $9.5 \%$ bandwidth at $2 \mathrm{GHz}$ has been achieved. Maximum bandwidth of $16 \%$ has been achieved ranging from $2.25-2.65 \mathrm{GHz}$ using aperture coupled feeding, which is not suitable for 3.5 $\mathrm{GHz}$ WiMAX system [6]. The Stacked dual wide slit loaded rectangular microstrip antenna gives a broad bandwidth of $27 \%$ and $24 \%$ reduction in antenna size but due to stacking height of the antenna increases [7]. K.Mandal et al. has increased the bandwidth of microstrip antenna up to $27 \%$ using staggered effect, but the large size of the antenna is a major problem [8]. Ahmed et al [9] has proposed a wide-band small size microstrip antenna proximately coupled to a hook shape probe. The patch size is reduced to $25 \%$ with over $30 \%$ matching band-width. The microstrip antenna with $47 \%$ bandwidth is proposed but it uses thick substrate, which increases the height of the antenna [10]. Khanna and Srivastava [11] designed a square patch antenna with modified edges and square fractal slots with a bandwidth of 30\%. Tyagi and Vyas [12] designed a slotted Ushaped microstrip antenna with PBG structure which has an impedance bandwidth of $35 \%$. Diego et al [13] designed a wide band E shaped patch antenna that provides an impedance bandwidth of about $29.8 \%$ by cutting a zigzag slot on the patch. Kaur et al [14] has designed a U-shaped slot loaded inverted circular patch antenna with maximum bandwidth of $24.2 \%$.

In this paper, a single layer coaxially fed slot loaded microstrip patch antenna with modified ground plane has been presented. The proposed antenna covers some important design aspects of microstrip patch antennas, such as (i) size reduction, (ii) narrowband multi-resonance characteristics, and (iii) enhancement of bandwidth. The novelty of our work is narrowband and wideband resonance characteristics in compact size by a single antenna without using thick foam substrate, shorting pin, stacked patch, multiple radiating patch element, complex fractal slots or modifications in the feed. The proposed antenna is successfully designed with thin, inexpensive, low dielectric constant FR-4 substrate. The structure of the proposed antenna is very simple and easy to fabricate. The wideband operation is achieved by defecting only $8 \%$ of the total ground plane area. The proposed antenna provides much better operating bandwidth $(62.3 \%)$ and size reduction (70\%) with simple and new structure in comparison to the previously reported antennas [1-14].

\section{Antenna Configuration}

The design of the antenna begins with a conventional rectangular microstrip antenna with patch length $\left(L_{P}\right)=10 \mathrm{~mm}$ and width $\left(W_{P}\right)=14 \mathrm{~mm}$. The FR-4 substrate chosen for realizing the antenna has dielectric constant, $\varepsilon_{r}=4.4$ and thickness $(h)$ of $1.5875 \mathrm{~mm}$. The geometry of the proposed antenna is shown in Figure 1. The structure of the modified rectangular patch is shown in Figure 1(a). The optimal dimensions of the proposed slot loaded patch are $\mathrm{W}_{\mathrm{P}}=14 \mathrm{~mm}, \mathrm{~L}_{\mathrm{P}}=10 \mathrm{~mm}, \mathrm{~W}_{\mathrm{P} 1}=\mathrm{W}_{\mathrm{P} 2}=0.5 \mathrm{~mm}, \mathrm{~L}_{\mathrm{P} 1}=\mathrm{L}_{\mathrm{P} 4}=5 \mathrm{~mm}, \mathrm{~L}_{\mathrm{P} 2}=$ $4.25 \mathrm{~mm}, \mathrm{~L}_{\mathrm{P} 3}=0.5 \mathrm{~mm}$. The structure of the proposed modified ground plane of the proposed antenna is shown in Figure 1(b). Narrowband resonance characteristics and also wide operating bandwidth are achieved when the ground plane of the slotted patch is modified with etched open ended asymmetric T-shaped slot. The desired result is achieved for ground plane of width $W_{g}=30 \mathrm{~mm}$ and Length $L_{g}=20 \mathrm{~mm}$. The width of the ground plane can be calculated using the empirical formula $W_{g}=W_{P}+10 \mathrm{~h}$ and length of the ground plane can be calculated by the empirical relation $L_{g}=L_{P}+6.25 \mathrm{~h}$, where $\mathrm{h}$ is the thickness of the FR-4 substrate. The optimal dimensions of the modified ground plane of proposed antenna are $W_{g}=30 \mathrm{~mm}, L_{g}=20 \mathrm{~mm}, W_{g 1}=3 \mathrm{~mm}, W_{g 2}=13.5 \mathrm{~mm}$, $W_{g 3}=3 \mathrm{~mm}, L_{g 1}=11 \mathrm{~mm}, L_{g 2}=5 \mathrm{~mm}, L_{g 3}=4 \mathrm{~mm}$. The feeding point is located at a 
position $(X, Y)=(4 \mathrm{~mm}, 6 \mathrm{~mm})$ from centre $(X=0 \mathrm{~mm}, Y=0 \mathrm{~mm})$ of the patch. All the parameters such as position of the slots on the patch and ground plane, dimension of the slots and position of the feed point were finalized by parametric study through a number of simulations using a method of moment based full wave commercial EM software IE3D [15]. The top view of the proposed antenna is shown in Figure 2. The prototype of the fabricated antenna is shown in Figure 3. The fabricated structure of the patch is shown in Figure 3(a), and the modified ground plane is shown in Figure 3(b).

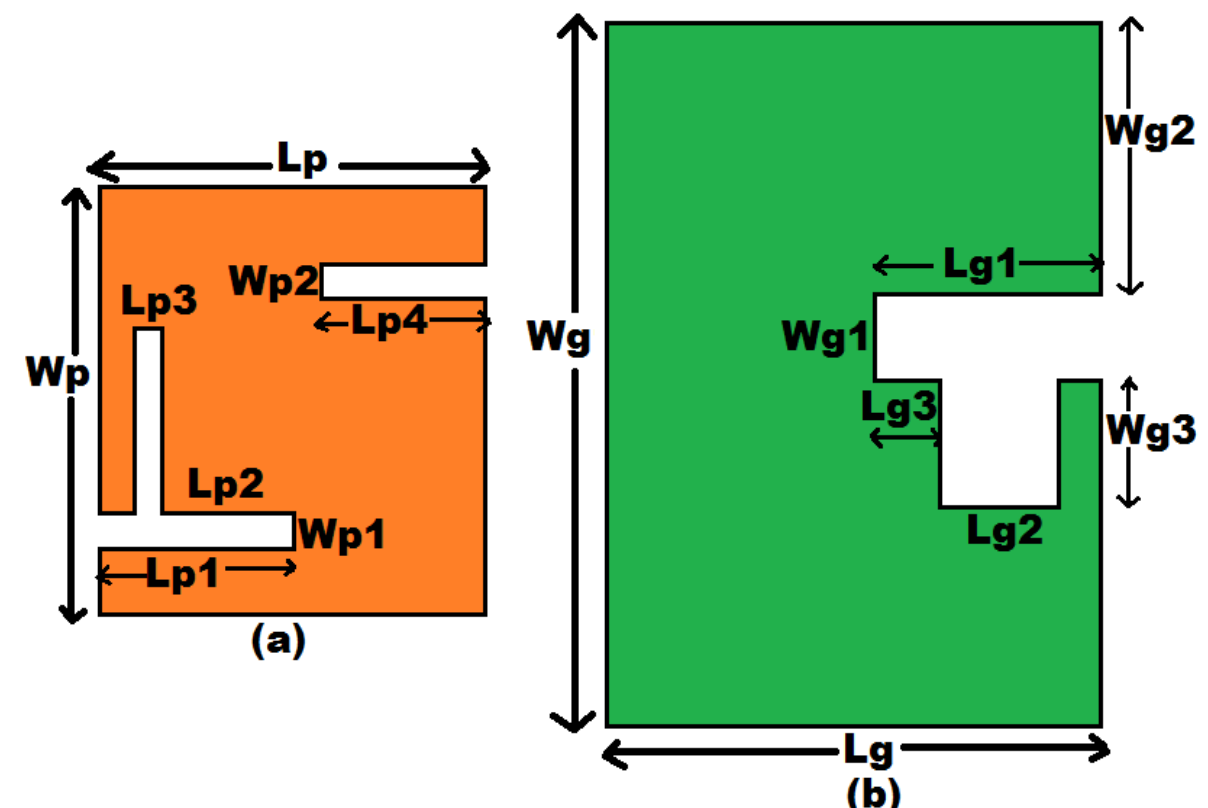

(b)

Figure 1. Structure of (a) Modified Rectangular Patch (b) Modified Ground Plane of the Proposed Antenna

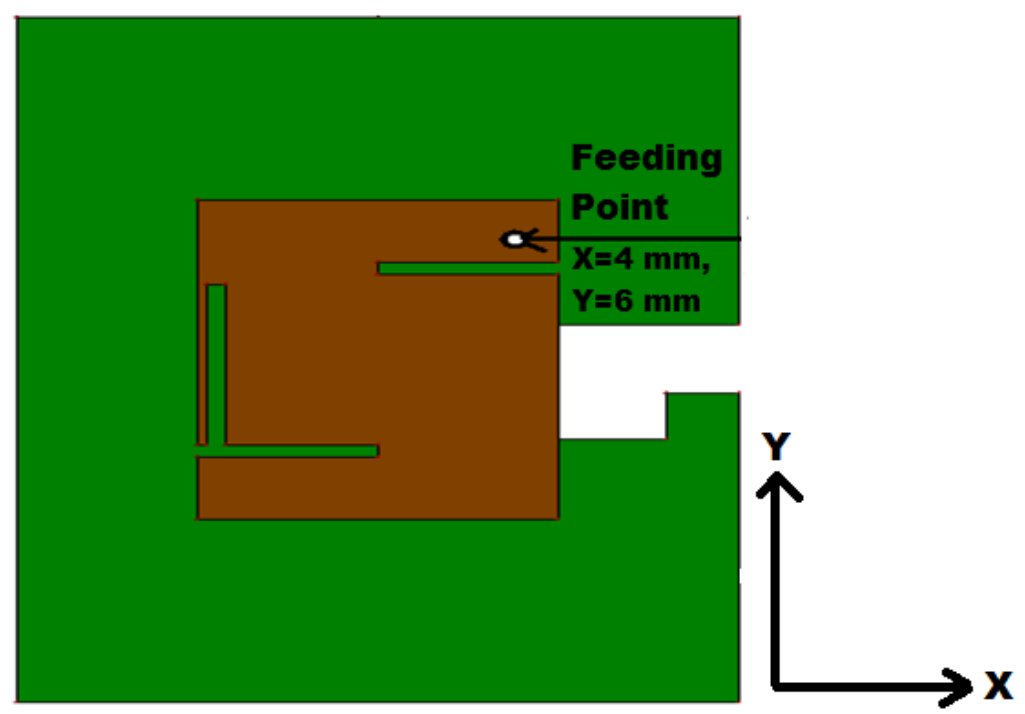

Figure 2. Top View of Proposed Antenna 


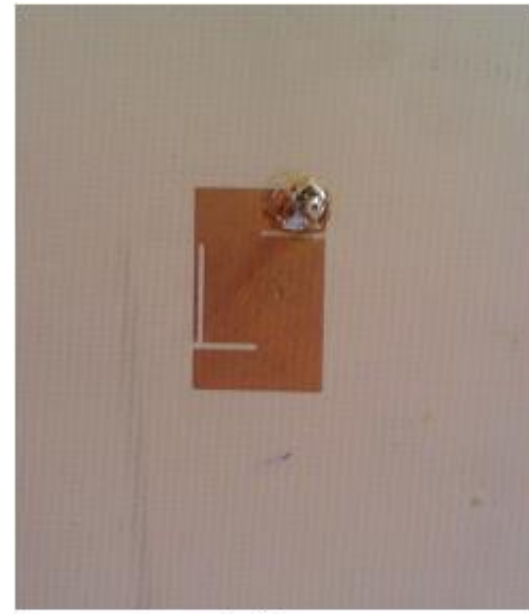

(a)

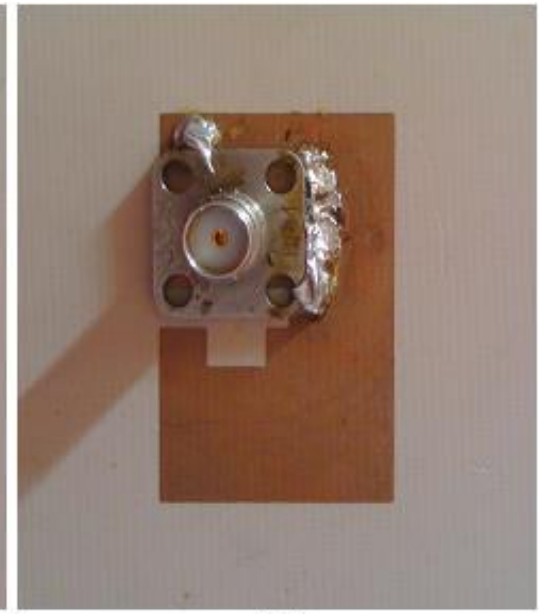

(b)

\section{Figure 3. Fabricated Structure of the Proposed Antenna (a) Patch (b) Modified ground plane}

\section{Parametric Study of the Proposed Antenna}

The structural effect of the ground plane on the antenna performance is investigated by mounting the proposed patch antenna on either of two different types of ground plane. The first is a conventional perfect electrical conductor (PEC) ground plane i.e., without modification in the ground plane and the other is a modified ground plane (MGP). Figure 4 compares the simulated reflection coefficient versus frequency of the conventional rectangular microstrip patch antenna (CRMPA) and proposed patch antenna with simple and modified ground plane. It can be observed from Figure 4 that in Case I, the conventional rectangular microstrip patch antenna resonates at $6.45 \mathrm{GHz}$. The antenna shows multifrequency operation with narrowband resonance characteristics, when designed with modified patch but simple (without slot) ground plane (Case II). The proposed antenna shows narrow band resonant frequencies and also wide operating bandwidth due to modified ground plane (MGP) structure (Case III). The effect of variations in the dimensions of the ground plane slots on the resonant characteristics of the proposed antenna were investigated by parametric study. The effective parameters are investigated by varying one parameter at a time when fixing the other parameters. The simulated results of variations in resonant frequency and reflection coefficient of the proposed antenna as a function of ground plane slots are shown in Figures 5-8. The proposed antenna with its optimum dimension provides bandwidth of $57.3 \%$ from 2.49 to $4.49 \mathrm{GHz}$ and two distinct narrow resonant frequencies at 5.905 and $7.76 \mathrm{GHz}$. Figure 5 indicates that if the length of the slot $\left(L_{g 1}\right)$ on the ground plane is decreased from $11 \mathrm{~mm}$ to $9 \mathrm{~mm}$ keeping other optimum dimension parameters fixed then the higher order resonant frequency is not excited below $-10 \mathrm{~dB}$ and fractional bandwidth of the antenna is decreased to $13 \%(3.88-4.42 \mathrm{GHz})$. Further increase in $L_{g 1}$ from $11 \mathrm{~mm}$ to $13 \mathrm{~mm}$ provides fractional bandwidth of only $33.7 \%(3.03-4.26 \mathrm{GHz})$ and higher resonant frequency is excited at $7.55 \mathrm{GHz}$ with reflection coefficient $-15 \mathrm{~dB}$. It is noticed from Figure 6 that the fractional bandwidth of proposed antenna remains almost unchanged $(55 \%)$ with further increase or decrease in ground plane slot parameter $\left(L_{g 2}\right)$ compared to proposed slot dimension. But the higher order resonant frequency is not excited when the value of $L_{g 2}$ decreases to $4 \mathrm{~mm}$. It is observed from Figure 7 that if the dimension of $W_{g 1}$ is decreased from proposed value $(3 \mathrm{~mm})$ to $1 \mathrm{~mm}$, the higher order resonant frequency is not excited below $-10 \mathrm{~dB}$ and the fractional bandwidth of the antenna decreases to $52.9 \%$ $(2.68-4.61 \mathrm{GHz})$. The higher order resonant frequency can be easily exited below $-10 \mathrm{~dB}$ 
level by increasing the dimension of ground plane slot parameter $\left(W_{g 1}\right)$. It is clearly observed from Figure 8 that the fractional bandwidth (57.3\%) of the proposed antenna remains unaltered with further increase in $W_{g 3}$ parameter. But when the dimension of $W_{g 3}$ is decreased to $1 \mathrm{~mm}$ compared to proposed slot dimension $\left(W_{g 3}=3 \mathrm{~mm}\right)$, the fractional bandwidth of the antenna is reduced to $48.6 \%(2.57-4.22 \mathrm{GHz})$ and also the higher order resonant frequency is not excited. So, it can be concluded that the resonance behavior of the proposed antenna is greatly influenced by ground plane slot parameters and any further increase or decrease in these parameters than the proposed dimensions will drastically change the desired characteristics of the proposed antenna. The results of Figures 5-8 are summarized in Table 1.

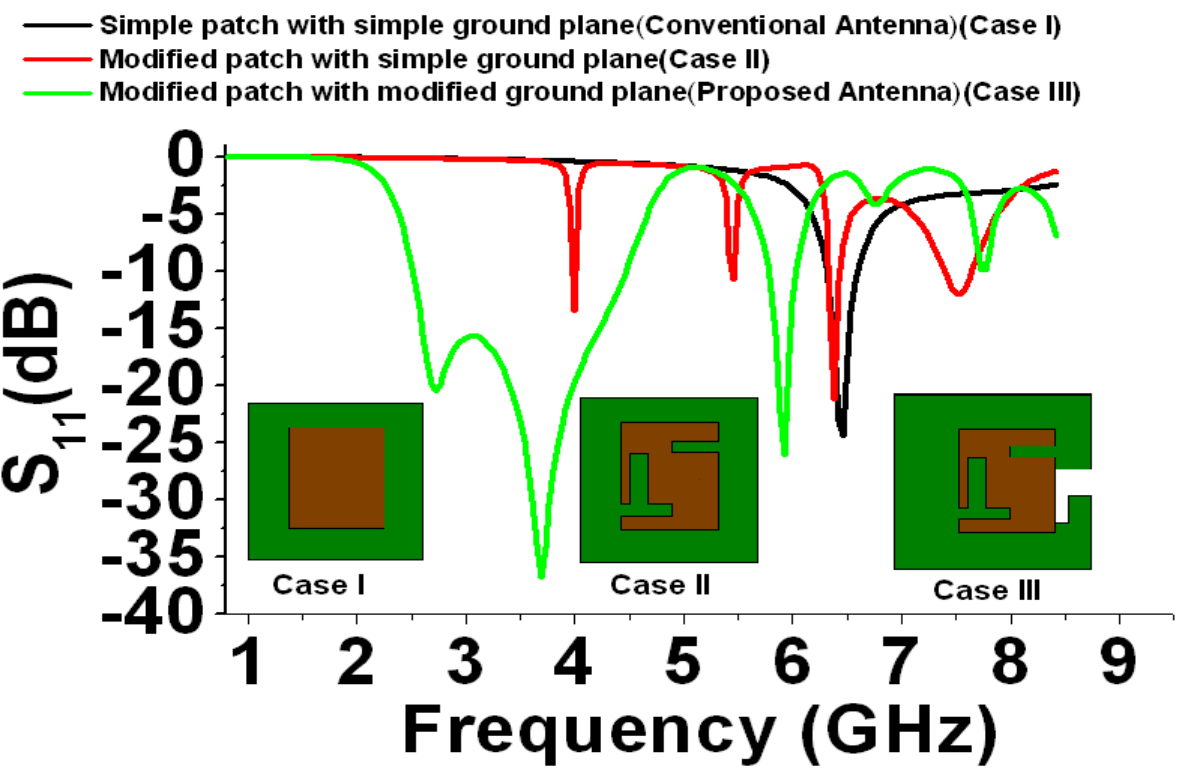

Figure 4. $\mathrm{S}_{11}$ Versus Frequency Comparisons in Different Cases

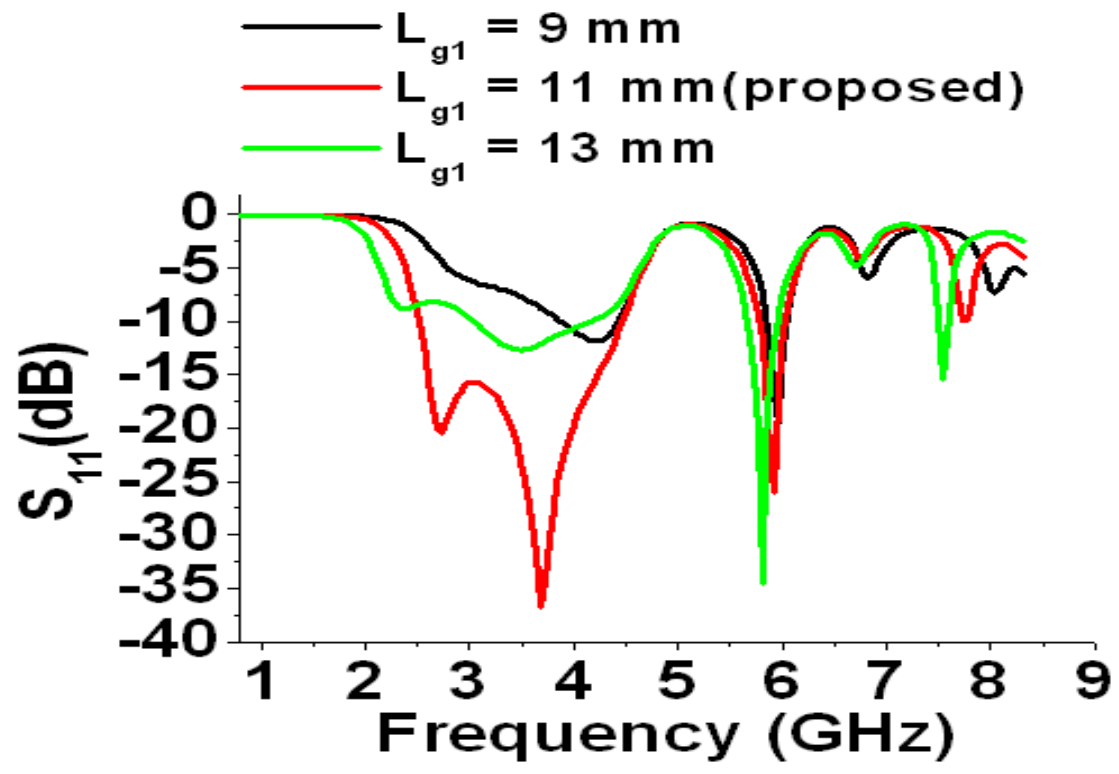

Figure 5. $S_{11}$ Vs. Frequency as a Function of $L_{g 1}$ 


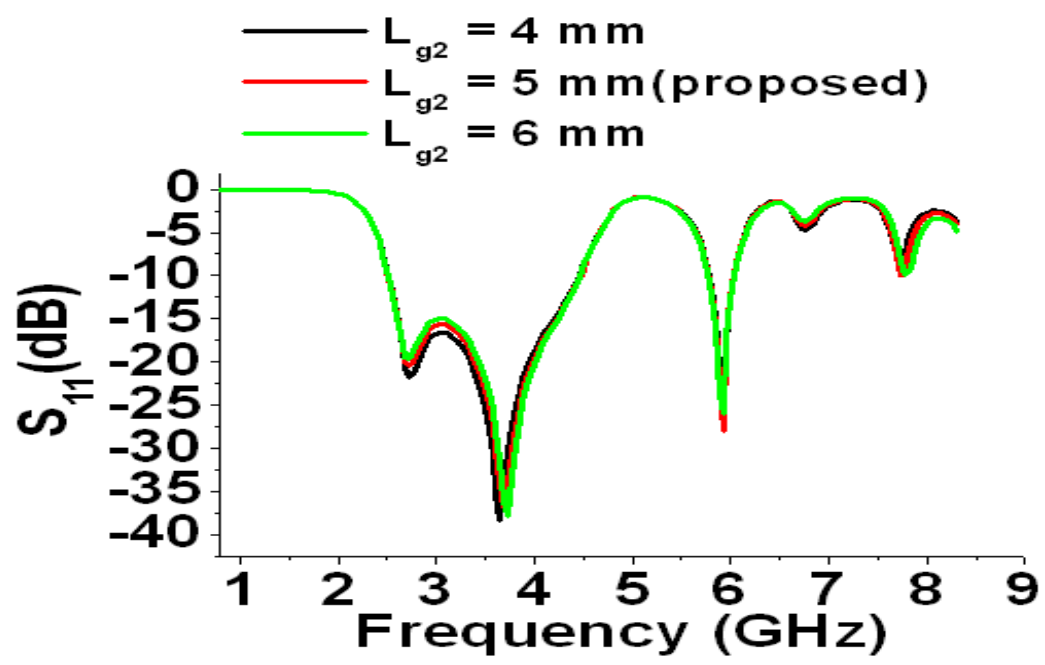

Figure 6. $S_{11}$ Vs. Frequency as a Function of $L_{g 2}$

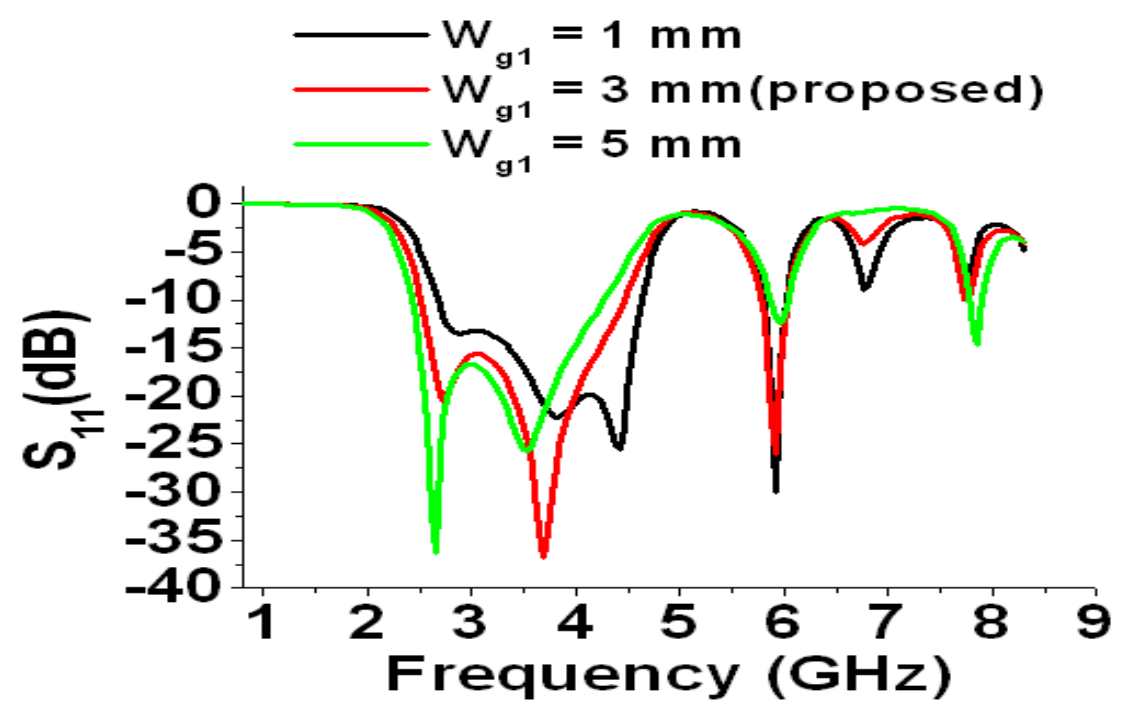

Figure 7. $S_{11}$ Vs. Frequency as a Function of $W_{g 1}$

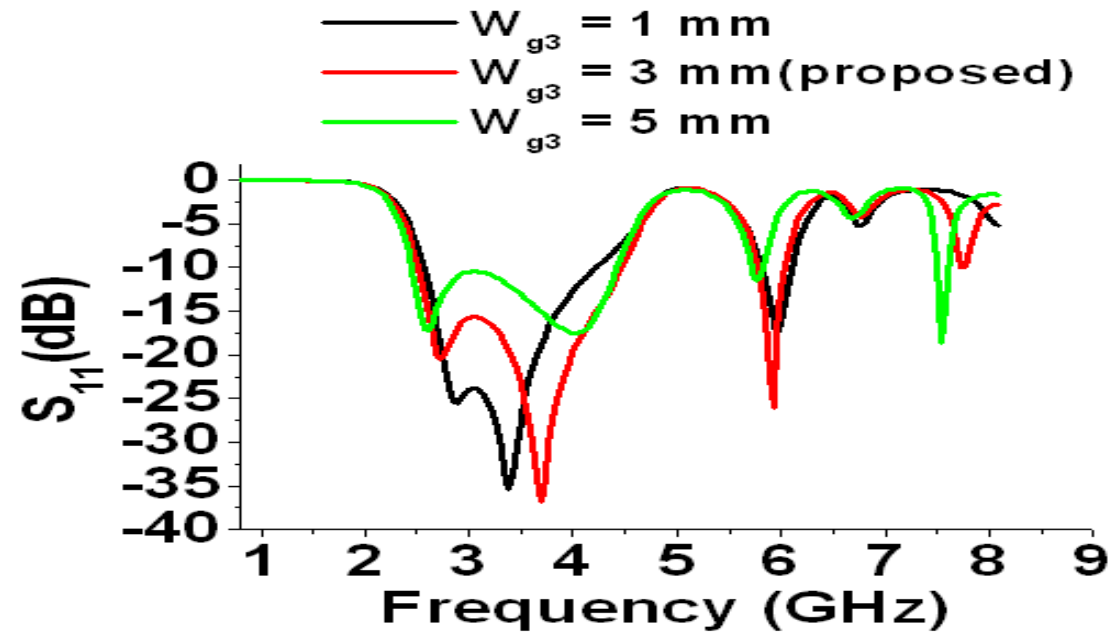

Figure 8. $S_{11}$ Vs. Frequency as a Function of $W_{g 3}$ 


\section{Table 1. Simulated Results of Proposed Antenna for Variations of Ground Plane Parameters}

\begin{tabular}{|c|c|c|c|c|}
\hline $\begin{array}{c}\text { Ground } \\
\text { plane slot } \\
\text { dimensions } \\
(\mathbf{m m})\end{array}$ & $\begin{array}{c}\text { Ratio of } \\
\text { removed } \\
\text { area/ } \\
\text { Total ground } \\
\text { Plane area } \\
(\%) \\
\end{array}$ & $\begin{array}{l}\text { Operating } \\
\text { centre } \\
\text { frequency } \\
(\mathbf{G H z})\end{array}$ & $\begin{array}{c}-10 \mathrm{~dB} \\
\text { bandwidth } \\
\text { (GHz) }\end{array}$ & $\begin{array}{c}\text { Fractional } \\
\text { Bandwidth } \\
(\%)\end{array}$ \\
\hline$L_{g 1}=9$ & 7 & $\begin{aligned} f_{c 1} & =4.15 \\
f_{c 2} & =5.955\end{aligned}$ & $\begin{array}{l}(3.88-4.42) \\
(5.88-6.03) \\
\end{array}$ & $\begin{array}{c}13 \\
2.51 \\
\end{array}$ \\
\hline $\begin{array}{c}L_{g 1}=11 \\
\text { (Proposed) }\end{array}$ & 8 & $\begin{array}{c}f_{c 1}=3.49 \\
f_{c 2}=5.905 \\
f_{c 3}=7.76\end{array}$ & $\begin{array}{l}(2.49-4.49) \\
(5.78-6.03) \\
(7.74-7.78)\end{array}$ & $\begin{array}{c}57.3 \\
4.23 \\
0.5 \\
\end{array}$ \\
\hline$L_{g 1}=13$ & 9 & $\begin{array}{c}f_{c 1}=3.645 \\
f_{c 2}=5.80 \\
f_{c 3}=7.55\end{array}$ & $\begin{array}{l}(3.03-4.26) \\
(5.68-5.92) \\
(7.53-7.57)\end{array}$ & $\begin{array}{c}33.7 \\
4.13 \\
0.5 \\
\end{array}$ \\
\hline$L_{g 2}=4$ & 7.5 & $\begin{array}{c}f_{c 1}=3.49 \\
f_{c 2}=5.895\end{array}$ & $\begin{array}{l}(2.53-4.45) \\
(5.80-5.99)\end{array}$ & $\begin{array}{c}55 \\
3.22 \\
\end{array}$ \\
\hline $\begin{array}{c}L_{g 2}=5 \\
\text { (Proposed) }\end{array}$ & 8 & $\begin{array}{c}f_{c 1}=3.49 \\
f_{c 2}=5.905 \\
f_{c 3}=7.76\end{array}$ & $\begin{array}{l}(2.49-4.49) \\
(5.78-6.03) \\
(7.74-7.78)\end{array}$ & $\begin{array}{c}57.3 \\
4.23 \\
0.5\end{array}$ \\
\hline$L_{g 2}=6$ & 8.5 & $\begin{array}{c}f_{c 1}=3.49 \\
f_{c 2}=5.895 \\
f_{c 3}=7.76\end{array}$ & $\begin{array}{l}(2.53-4.45) \\
(5.80-5.99) \\
(7.74-7.78)\end{array}$ & $\begin{array}{c}55 \\
3.22 \\
0.5\end{array}$ \\
\hline$W_{g 1}=1$ & 4.33 & $\begin{array}{l}f_{c 1}=3.645 \\
f_{c 2}=5.895\end{array}$ & $\begin{array}{l}(2.68-4.61) \\
(5.80-5.99) \\
\end{array}$ & $\begin{array}{l}52.9 \\
3.22 \\
\end{array}$ \\
\hline $\begin{array}{c}W_{g 1}=3 \\
\text { (Proposed) }\end{array}$ & 8 & $\begin{array}{c}f_{c 1}=3.49 \\
f_{c 2}=5.905 \\
f_{c 3}=7.76\end{array}$ & $\begin{array}{l}(2.49-4.49) \\
(5.78-6.03) \\
(7.74-7.78)\end{array}$ & $\begin{array}{c}57.3 \\
4.23 \\
0.5 \\
\end{array}$ \\
\hline$W_{g 1}=5$ & 11.66 & $\begin{array}{c}f_{c 1}=3.335 \\
f_{c 2}=5.955 \\
f_{c 3}=7.84\end{array}$ & $\begin{array}{l}(2.41-4.26) \\
(5.88-6.03) \\
(7.80-7.88)\end{array}$ & $\begin{array}{l}55.4 \\
2.51 \\
1.02\end{array}$ \\
\hline$W_{g 3}=1$ & 6.33 & $\begin{array}{l}f_{c 1}=3.395 \\
f_{c 2}=5.955\end{array}$ & $\begin{array}{l}(2.57-4.22) \\
(5.84-6.07) \\
\end{array}$ & $\begin{array}{l}48.6 \\
3.86 \\
\end{array}$ \\
\hline $\begin{array}{c}W_{g 3}=3 \\
\text { (Proposed) }\end{array}$ & 8 & $\begin{array}{c}f_{c 1}=3.49 \\
f_{c 2}=5.905 \\
f_{c 3}=7.76\end{array}$ & $\begin{array}{l}(2.49-4.49) \\
(5.78-6.03) \\
(7.74-7.78) \\
\end{array}$ & $\begin{array}{c}57.3 \\
4.23 \\
0.5 \\
\end{array}$ \\
\hline$W_{g 3}=5$ & 9.66 & $\begin{array}{l}f_{c 1}=3.43 \\
f_{c 2}=5.76 \\
f_{c 3}=7.55\end{array}$ & $\begin{array}{l}(2.45-4.41) \\
(5.72-5.80) \\
(7.53-7.57) \\
\end{array}$ & $\begin{array}{c}57.3 \\
1.38 \\
0.5 \\
\end{array}$ \\
\hline
\end{tabular}

\section{Analysis and Working of the Proposed Antenna}

The working principle of the proposed antenna can be explained with the help of surface current distributions. The effect of each optimized ground plane slot on the resonance behavior of the proposed antenna is depicted in Figure 9. The current distribution at the modified ground plane of the proposed antenna at different frequencies is shown in Fig. 10. The maximum surface current density varies from about $22.6 \mathrm{~A} / \mathrm{m}$ (at $3.22 \mathrm{GHz}$ ) to $163.5 \mathrm{~A} / \mathrm{m}$ (at 5.905 GHz). As depicted in Figure 9, the resonance behavior of the antenna changes drastically with the addition of each optimized slot on the ground 
plane of the proposed antenna. In Case I, Due to the introduction of optimized horizontal slot of dimensions, $W_{g 1}=3 \mathrm{~mm}, L_{g 1}=11 \mathrm{~mm}$ on the ground plane, the antenna resonates at $6.0,8.30 \mathrm{GHz}$ with reflection coefficients $-16.4,-19.2 \mathrm{~dB}$, respectively. In this case the antenna also provides a broad impedance bandwidth of $1570 \mathrm{MHz}$ (2.57$4.14 \mathrm{GHz})$ for $\mathrm{S}_{11}<-10 \mathrm{~dB}$. For the $(2.57-4.14 \mathrm{GHz})$ operation, [see Figure 10(a)], it is observed that surface current density is much stronger around the horizontal slot $\left(W_{g 1}, L_{g 1}\right)$ at the centre frequency $3.355 \mathrm{GHz}$ of this band. Finally in case II, the incorporation of an optimized vertical slot $L_{g 2}=5 \mathrm{~mm}, W_{g 3}=3 \mathrm{~mm}$ has further reduced the resonant frequencies to 5.905 and $7.76 \mathrm{GHz}$, respectively. It has also increased the operating bandwidth of the antenna. The frequency bands get wider by $430 \mathrm{MHz}$, and the new operating bandwidth (2000 MHz) of the antenna ranges from 2.49 to $4.49 \mathrm{GHz}$. It is verified from Figure 10(b) that at $4.35 \mathrm{GHz}$, surface current density is much stronger around the vertical slot $\left(L_{g 2}, W_{g_{3}}\right)$, which creates extra resonance path and varies the resonant frequency of the antenna. It is observed from Figure 10 (c) that for $5.905 \mathrm{GHz}$, the surface current is mainly concentrated around the horizontal slot $\left(W_{g 1}, L_{g 1}\right)$ for which this resonance mode is excited. But due to lengthening of the surface current around the vertical slot $\left(L_{g 2}, W_{g 3}\right)$, the resonant frequency decreases to $5.905 \mathrm{GHz}$. So, the surface current also partly circulates around vertical slot at $5.905 \mathrm{GHz}$. For the $7.76 \mathrm{GHz}$ operation [see Figure 10(d)], it is observed that the surface current circulates around both horizontal and vertical slot but it is mainly concentrated around the vertical slot $\left(L_{g 2}, W_{g 3}\right)$ for which it generated and controlled. Thus, both from the $S_{11}$ characteristic curves and surface current distributions, we can clearly comprehend the function of the related geometrical mechanism of the proposed antenna at three resonant modes. The modified ground plane disturbs the shield current distribution in the ground plane. As a result they change the inductance and capacitance. Basically modified ground plane increases the value of inductance and capacitance. Due to modifications in the ground plane, a parasitic field or fringing is created and this creation of fringing field increases the coupling between the conducting patch and ground plane. This increased coupling enhances the bandwidth of operation of the antenna. The bandwidth enhancement process may also be realized by obtaining multiple resonant frequencies that radiate very close to each other under $-10 \mathrm{~dB}$ levels, and their resonance envelopes provide the desired bandwidth.

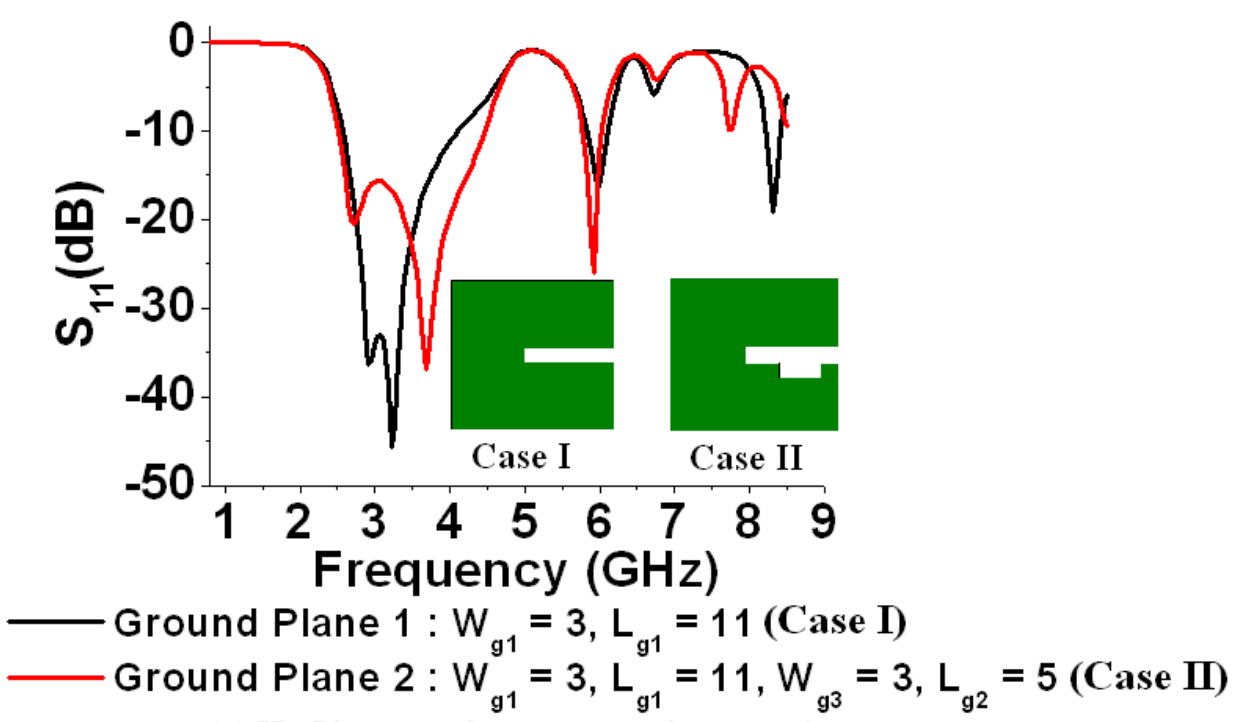

\section{(All dimensions are in $\mathrm{mm}$ )}

Figure 9. Effect of Each Optimized Ground Plane Slot 


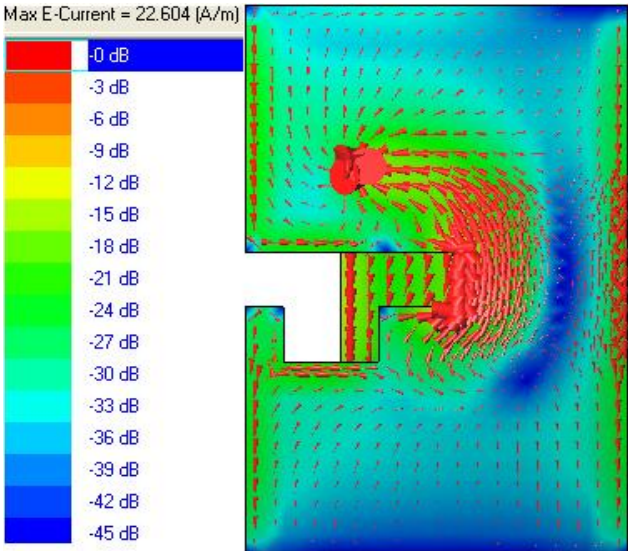

(a)

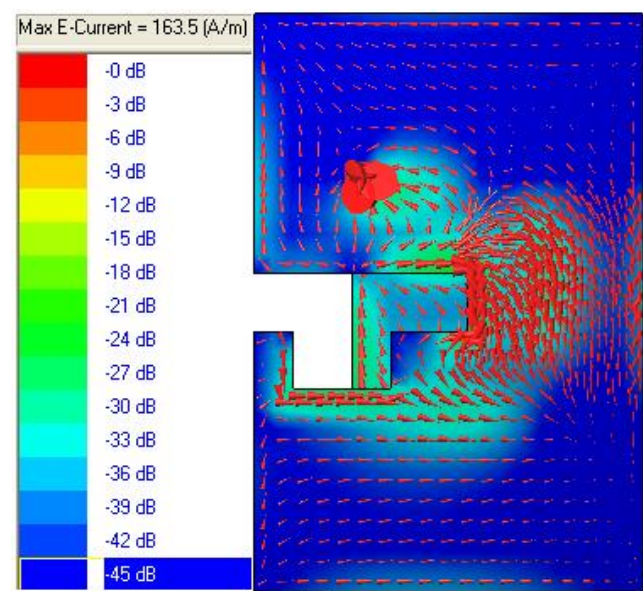

(c)

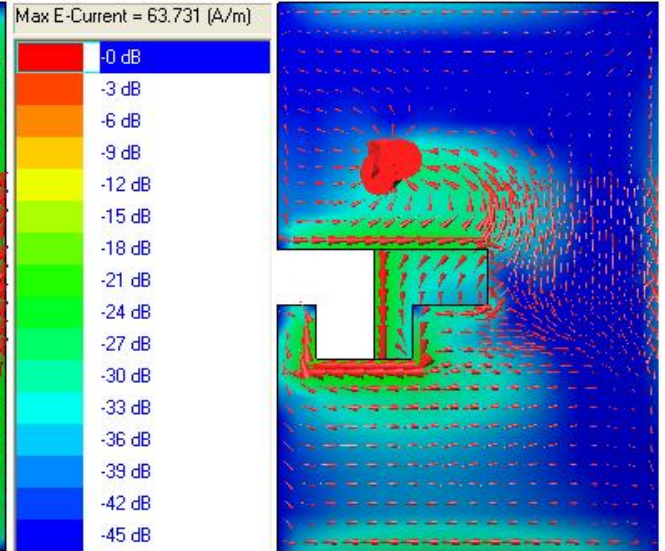

(b)

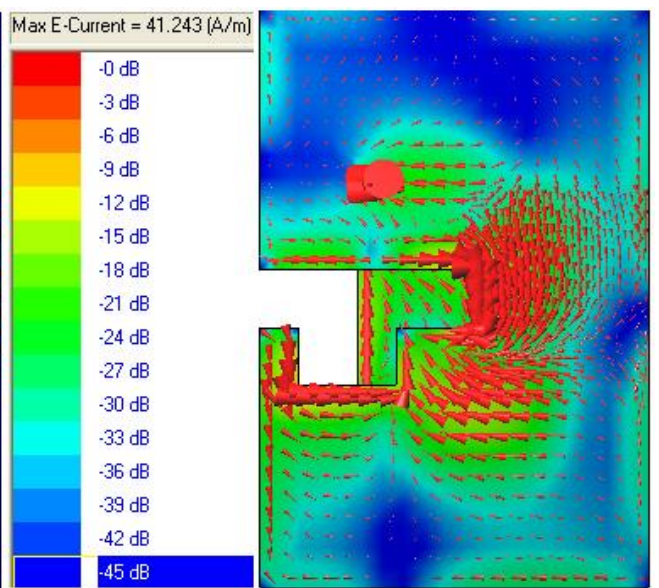

(d)

Figure 10. Current Distribution on the Ground Plane of Proposed Antenna at (a) $3.355 \mathrm{GHz}$, (b) $4.35 \mathrm{GHz}$, (c) $5.905 \mathrm{GHz}$, and (d) $7.76 \mathrm{GHz}$

\section{Results and Discussion}

The reflection coefficient of the fabricated antenna was measured using Agilent E5071B vector network analyzer. The agreement between the simulated and measured results is reasonably good. The discrepancy between the measured and simulated results may be due to the effect of improper soldering of SMA connector or fabrication tolerance. The simulated and measured reflection coefficient of proposed antenna is shown in Figure 11. The results of Figure 11 are summarized in Table 2. The measured result shows that the size of the proposed antenna has been reduced by $70 \%$ in comparison to the conventional rectangular microstrip antenna operating at $3.675 \mathrm{GHz}$ with patch area $(19 \mathrm{x}$ $25 \mathrm{~mm}^{2}$ ). The $\mathrm{E}$ and $\mathrm{H}$ plane radiation pattern of the proposed antenna is shown in Figure 12(a)-(c). The nearly bidirectional characteristics are achieved due to partial removal of conducting material below the radiating patch. The removed area is only $8 \%$ of the total ground plane dimension. Depending on the shape and dimensions of the defect on the ground plane, the shielded current distribution in the ground plane is disturbed which results in a controlled excitation and propagation of the electromagnetic waves through the substrate layer. This disturbance will cause change in radiation characteristics of the proposed antenna [16]. It is notable that cross polarization levels of the antenna are improved due to modified ground structure. Figure 12(a) indicates $20 \mathrm{~dB}$ higher co polar patterns than cross polar pattern for both $\mathrm{E}$ and $\mathrm{H}$ plane at $2.75 \mathrm{GHz}$. It is seen from 
Figure 12 (b) that the radiation characteristics of the proposed antenna shows good crosspolarization level of $-28 \mathrm{~dB}$ in comparison to the co polarization level of the main lobe at E plane and $\mathrm{H}$ plane for the centre frequency $3.675 \mathrm{GHz}$ of the broadband frequency range. So, the proposed antenna shows considerably good cross polar pattern over the entire impedance bandwidth $(2.49-4.49 \mathrm{GHz})$. The antenna radiation patterns are almost identical in shape with in broadband frequency range. However, Figure 12(c) suggests that at narrowband frequency $5.905 \mathrm{GHz}$, co polar pattern is nearly $30 \mathrm{~dB}$ higher than cross polar pattern for $\mathrm{E}$ plane while it is $16 \mathrm{~dB}$ higher than cross polar pattern for $\mathrm{H}$ plane. So, the result of Figure 12 shows that isolation between co and cross polarization is quite high. Due to nearly bidirectional radiation characteristics, the proposed antenna may be used in bidirectional radar. The simulated and measured gain of the proposed antenna is shown in Figure 13. The measured peak gain of the antenna is about $2.70 \mathrm{dBi}$ at 3.7 $\mathrm{GHz}$, which is better than the peak gains of some previously reported band width enhanced microstrip antennas [17-20]. The peak gain is measured by applying gain comparison method, in which a pre calibrated standard gain horn antenna is used as a reference antenna for measurement. The simulated result of directivity and radiation efficiency of the proposed antenna is shown in Figure 14. Peak radiation efficiency of about $73 \%$ is achieved in the broad band operating range. Peak directivity of about $7.0 \mathrm{dBi}$ is obtained at $7.76 \mathrm{GHz}$. The VSWR of the proposed antenna is shown in Figure 15. The maximum VSWR lies within 1.7:1 at the desired frequencies.

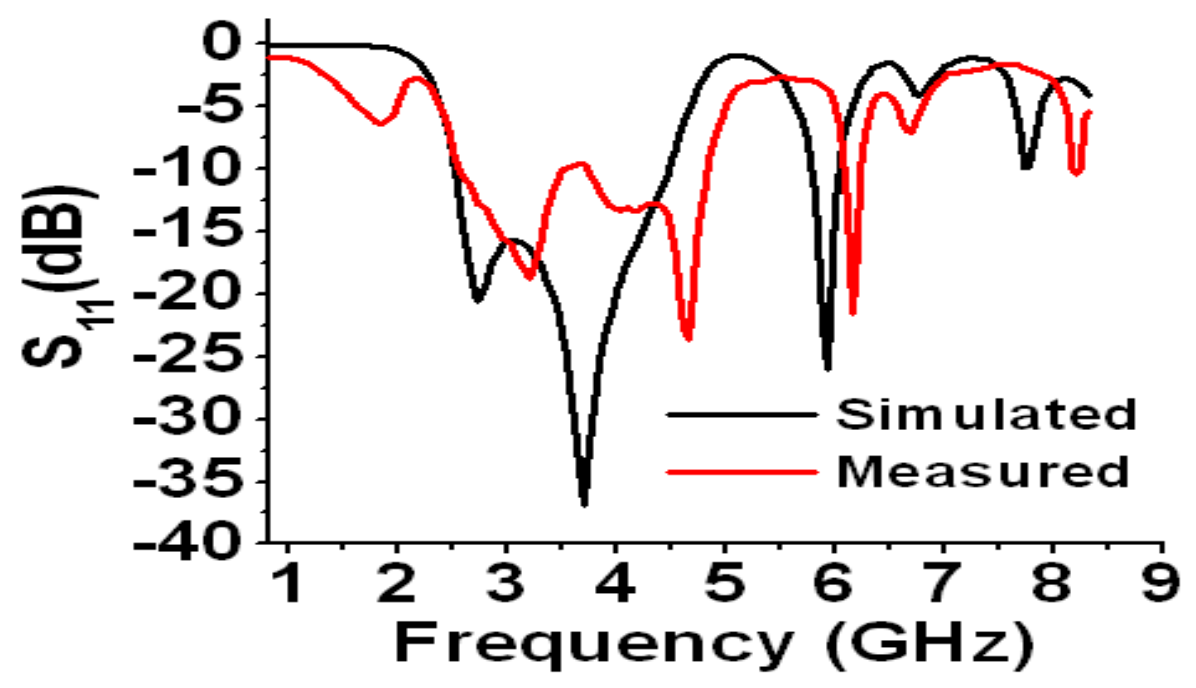

Figure 11. Reflection Coefficient of Proposed Antenna

Table 2. Simulated and Measured Results of Proposed antenna

\begin{tabular}{|c|c|c|c|}
\hline $\begin{array}{c}\text { Proposed } \\
\text { Antenna }\end{array}$ & $\begin{array}{c}\text { Operating } \\
\text { centre } \\
\text { frequency } \\
\text { (GHz) }\end{array}$ & $\begin{array}{c}-\mathbf{1 0} \text { dB Band } \\
\text { Width }(\mathbf{G H z})\end{array}$ & $\begin{array}{c}\text { Band-width } \\
\mathbf{( \% )}\end{array}$ \\
\hline Simulated & 3.49 & $(2.49-4.49)$ & 57.3 \\
\cline { 2 - 4 } & 5.905 & $(5.78-6.03)$ & 4.23 \\
\cline { 2 - 4 } & 7.76 & $(7.74-7.78)$ & 0.5 \\
\hline Measured & 3.675 & $(2.53-4.82)$ & 62.3 \\
\cline { 2 - 4 } & 6.165 & $(6.10-6.23)$ & 2.1 \\
\cline { 2 - 4 } & 8.18 & $(8.15-8.21)$ & 0.6 \\
\hline
\end{tabular}




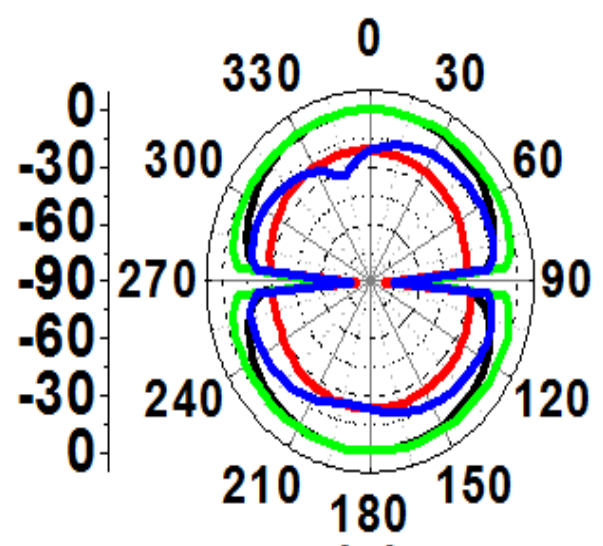

(a)

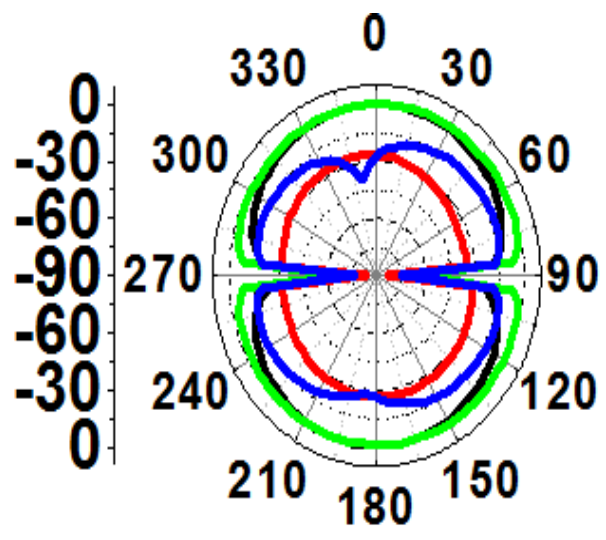

(b)

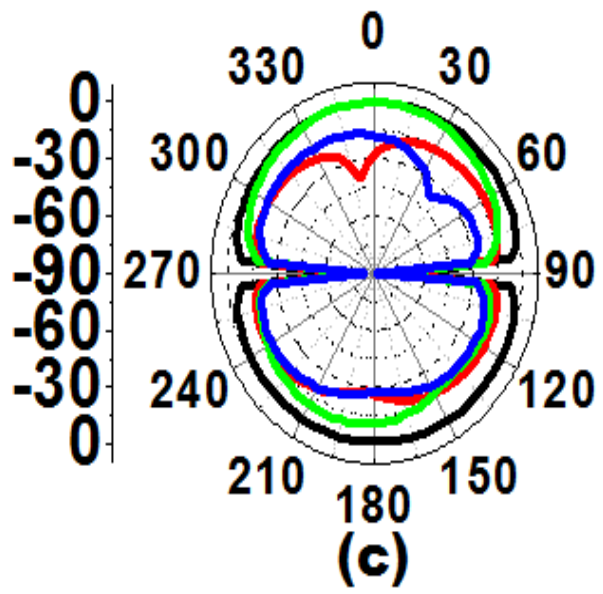

E plane Co polar

_E plane Cross polar

H plane Co polar

H plane Cross polar

Figure 12. E and H Plane Radiation Pattern at (a) $2.75 \mathrm{GHz}$, (b) $3.675 \mathrm{GHz}$, (c) $5.905 \mathrm{GHz}$

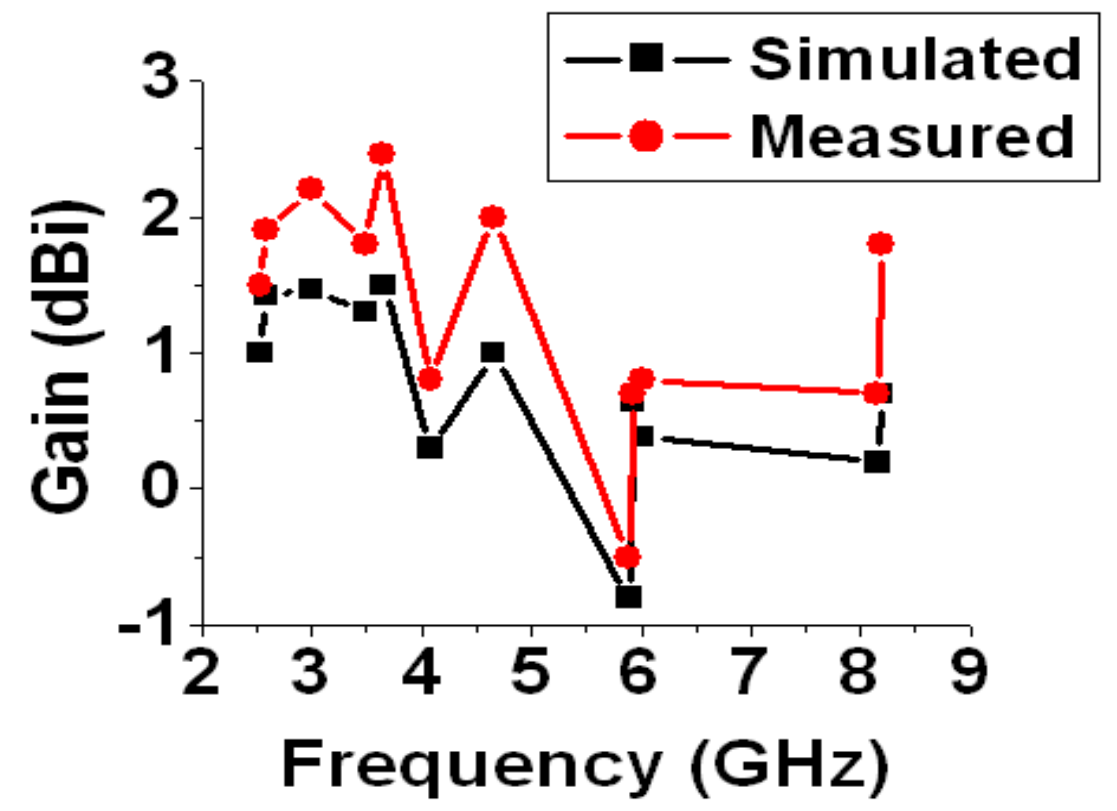

Figure 13. Gain Vs. Frequency Plot of the Proposed Antenna 


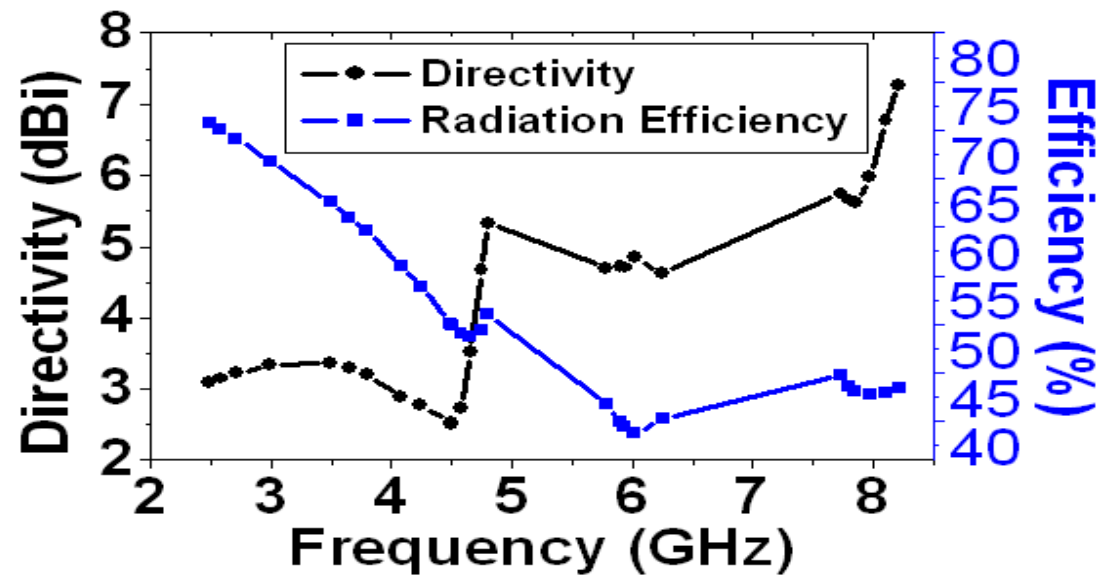

Figure 14. Directivity and Radiation Efficiency of the Proposed Antenna

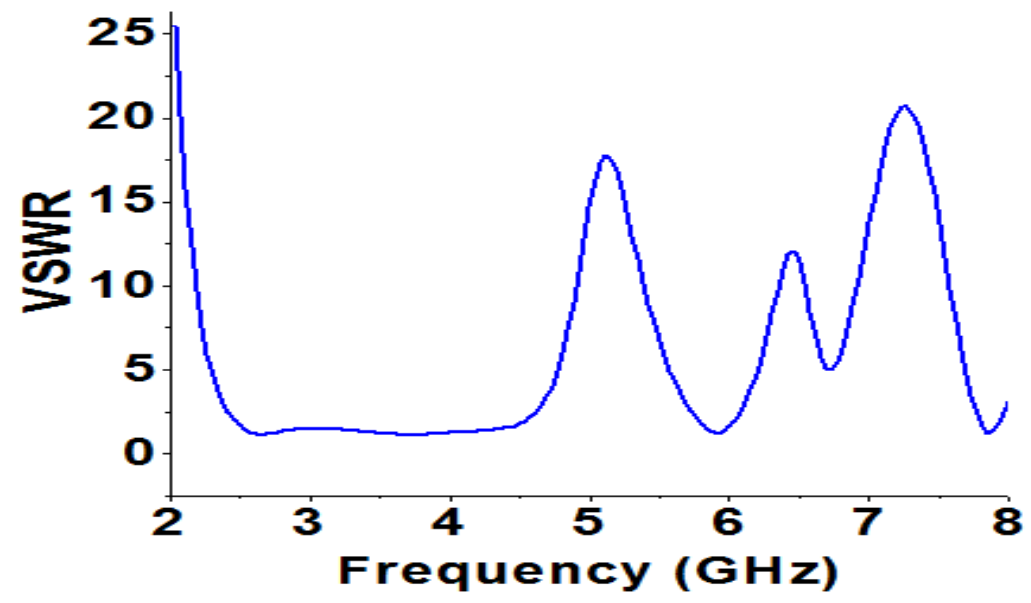

Figure 15. VSWR of the Proposed Antenna

\section{Conclusion}

This paper presents the design of a miniaturized slot loaded microstrip patch antenna with modified ground plane. Wideband and narrowband resonance characteristics are achieved by deforming the ground plane of the proposed antenna. Size reduction, multiresonance and broad-banding have been achieved by the single antenna. The size of the antenna has been reduced by $70 \%$ in comparison to conventional antenna. Furthermore, good radiation pattern characteristics with almost stable gain and acceptable amount of 3$\mathrm{dB}$ beam-widths are also obtained for the proposed compact antenna. The narrow band resonant frequencies of the proposed antenna may be utilized in government security systems. The wideband characteristics of the proposed antenna covers the bandwidth requirements of a number of modern wireless communication application bands such as WiMAX (2.5-2.69 GHz and 3.3-3.6 GHz), INSAT (4.5-4.8 GHz), IEEE 802.11y WiFi/WLAN (3.65-3.7 GHz), UMTS 3G expansion band $(2.5-2.7 \mathrm{GHz})$ and microwave $\mathrm{S}$ band $(2-4 \mathrm{GHz})$.

\section{References}

[1] Das, S, A. Karmakar, P.P. Sarkar, S.K. Chowdhury, "Design and Analysis of a novel open ended T shaped slot loaded Compact Multifrequency Microstrip patch Antenna”, Microwave Opt Technol Lett. Vol.56, (2014), 316-322. 
[2] Das, S, P.P.Sarkar, S.K.Chowdhury, "Investigations on miniaturized multifrequency microstrip patch antennas for wireless communication applications", J. Electromagn. Waves Appl. Vol. 27, (2013),11451162.

[3] Das,S, P.P.Sarkar, S.K.Chowdhury, "Design and analysis of a compact monitor-shaped multifrequency microstrip patch antenna", J. Electromagn. Waves Appl. Vol. 28, (2014), 827-837.

[4] Das, S, P.P.Sarkar, S.K.Chowdhury, "Analysis of an open-ended inverted L-shaped slot-loaded microstrip patch antenna for size reduction and multifrequency operation", J. Electromagn. Waves Appl. Vol. 29, (2015), 874-890.

[5] Cao, W, B. Zhang, H. Li, T. Yi, A. Liu, "A Broadband Microstrip Dipole Antenna Loaded with Shorted Pin", International Conference on Microwave and Millimeter Wave Technology (ICMMT), (2010), 1035-1037.

[6] Lai, C.H, T.-Y. Han and T.-R. Chen, "Broadband aperture-coupled microstrip antennas with low cross polarization and back radiation", Prog. Electromagn. Res. Lett., Vol.5, (2008), 187-197.

[7] Ushakiran, K, R.M.Yadahalli, R.M.Vani, P.V.Hunagund, "Compact broadband stacked dual wide slit loaded rectangular microstrip antenna”, Indian journal of Radio and Space physics, Vol.37, (2008), 366369.

[8] Mandal,K, S.Sarkar, and P.P.Sarkar, "Bandwidth enhancement of Microstrip antenna by staggering effect", Microwave Opt Technol Lett, Vol. 53, (2011), 2446-2447.

[9] Kishk,A.A, K. F. Lee, W. C. Mok, K.-M.Luk, "A Wide-Band Small Size Microstrip Antenna Proximately Coupled to a Hook Shape Probe”, IEEE Trans. Antennas Propag., Vol. 52, (2004), 59-65.

[10] Nasimuddin and Z.N.Chen, "Wideband microstrip antennas with sandwich substrate", Microw. Antennas Propag. Vol. 2, (2008), 538-546.

[11] Khanna,A, D.K. Srivastava, "Modified edged microstrip square patch antenna with square fractal slots for bluetooth applications", Int. J. Eng. Research Technol. Vol. 3, (2014) , 320-323.

[12] Tyagi, S, Kirti Vyas, "Bandwidth enhancement using slotted U-shape microstrip antenna with PBG ground", Int. J. Adv. Technol. Eng. Research Vol.3, (2013), 23-27.

[13] Caratelli, D, R. Cicchetti, G. B. Babik, and A. Faraone, "A perturbed E-shaped patch antenna for wideband WLAN applications", IEEE Trans. Antennas Propag., Vol. 54, (2006), 1871-1874.

[14] Kaur, P, S.K.Aggarwal, A. De, "Reconfigurable inverted circular patch antenna for wireless applications", International Journal of Advanced Science and Technology, Vol.70, (2014), 55-64.

[15] Zeland Software Inc., IE3D: MoM-based EM Simulator, Zeland Software Inc., Fremont, CA.

[16] Das, S, P. P. Sarkar, and S. K. Chowdhury, "Design and analysis of a compact triple band slotted microstrip antenna with modifed ground plane for wireless communication applications", Prog. Electromagn. Res. B., Vol. 60, (2014) ,215-225.

[17] Sim, C.Y.D, Y.W.Hsu C.H. Chao. "Dual broadband slot antenna design for WLAN applications", Microwave Opt Technol Lett, Vol.56, (2014), 983-988.

[18] Rautela, R.S, D.Viswakarma, "A ramp type planar monopole antenna for WLAN and WiMAX application”, Microwave Opt Technol Lett, Vol. 57, (2015), 1485-1487.

[19] Pei, J, A.G.Wang, S. Gao, W. Leng, "Miniaturized triple band antenna with a defected ground plane for WLAN/WiMAX applications", IEEE Antennas and Wireless Propag Lett, Vol. 10, (2011), 298-301.

[20] Misilmani, H. M. El, M.Al.Husseini, K.Y.Kabalan, A.El. Hajj, "A simple miniaturized triple band antenna for WLAN/WiMAX applications", PIERS Proceedings, Moscow, Russia, (2012), 608-612.

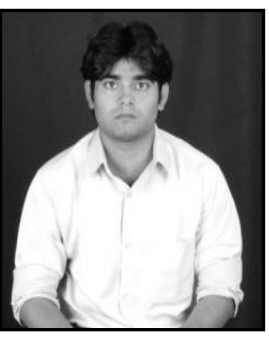

Sudipta Das, is working as an Assistant Profeesor in Department of Electronics and Communication Engineering. He is presently pursuing Ph.D from University of Kalyani, INDIA. His area of research interests are Microstrip Antenna and Filter design. He has contributed almost 30 international research articles in various journals. The Biography of Mr. Sudipta Das is shortlisted for inclusion in the Thirty-Eighth $\left(38^{\text {th }}\right)$ Edition of the Dictionary of International Biography published by the "International Biographical Centre" of Cambridge, England. The Biography of Mr. Sudipta Das is selected in Marquis Who's who in the World 2016 (33 ${ }^{\text {rd }}$ Edition). 


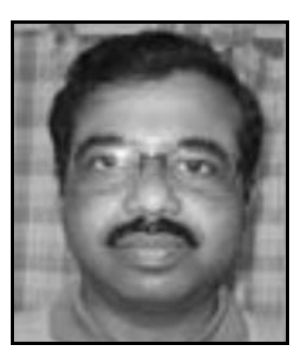

Partha Pratim Sarkar, obtained his Ph.D in engineering from Jadavpur University in the year 2002. He is presently working as Senior Scientific Officer (Professor Rank) at the Dept. of Engineering \& Technological Studies, University of Kalyani. His area of research includes, Microstrip Antenna, Microstrip Filter, Frequency Selective Surfaces, and Artificial Neural Network. He has contributed more than 250 research articles in various journals and conferences of repute. He is also a life Fellow of IETE.

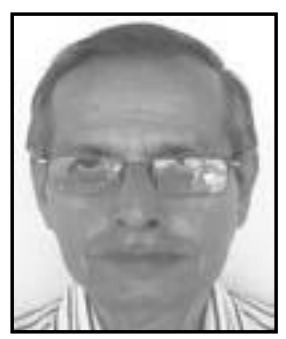

Santosh kr. Chowdhury, obtained his Ph.D in engineering from Jadavpur University in the year 1971. He is a Life senior member of IEEE, Life fellow of IETE, Fellow of IE, Fellow of West Bengal Academy of Science and Technology. His area of research includes Microstrip Antenna, Microstrip Filter, and Frequency Selective surfaces. He has contributed more than 400 international research articles in various journals and conferences of repute. 